\title{
COVID-19-associated coagulopathy and disseminated intravascular coagulation
}

\author{
Hidesaku Asakura ${ }^{1} \odot \cdot$ Haruhiko Ogawa ${ }^{2}$
}

Received: 15 October 2020 / Revised: 15 October 2020 / Accepted: 22 October 2020 / Published online: 7 November 2020

(c) Japanese Society of Hematology 2020

\begin{abstract}
The pathology of coronavirus disease 2019 (COVID-19) is exacerbated by the progression of thrombosis, and disseminated intravascular coagulation (DIC), and cytokine storms. The most frequently reported coagulation/fibrinolytic abnormality in COVID-19 is the increase in D-dimer, and its relationship with prognosis has been discussed. However, limits exist to the utility of evaluation by D-dimer alone. In addition, since the coagulation/fibrinolytic condition sometimes fluctuates within a short period of time, regular examinations in recognition of the significance of the examination are desirable. The pathophysiology of disseminated intravascular coagulation (DIC) associated with COVID-19 is very different from that of septic DIC, and both thrombotic and hemorrhagic pathologies should be noted. COVID-19 thrombosis includes macro- and microthrombosis, with diagnosis of the latter depending on markers of coagulation and fibrinolysis. Treatment of COVID19 is classified into antiviral treatment, cytokine storm treatment, and thrombosis treatment. Rather than providing uniform treatment, the treatment method most suitable for the severity and stage should be selected. Combination therapy with heparin and nafamostat is expected to develop in the future. Fibrinolytic therapy and adsorption therapy require further study
\end{abstract}

Keywords COVID-19 $\cdot$ Thrombosis · Disseminated intravascular coagulation · DIC · Cytokine storm · SARS-CoV-2

\section{Introduction}

Coronavirus disease 2019 (COVID-19) is an infection caused by severe acute respiratory syndrome coronavirus 2 (SARS-CoV-2). Eighty percent of infected individuals are asymptomatic or show only mild symptoms, but $20 \%$ of infected individuals become severely ill and 2-5\% die. Men are well known to be infected more frequently than women, and the elderly and patients with comorbidities (such as cardiovascular disease, hypertension, diabetes, and obesity) are more likely to develop more severe disease [1-3]. However,

Hidesaku Asakura

hasakura@staff.kanazawa-u.ac.jp

Haruhiko Ogawa

h-ogawa@jintikai.com

1 Department of Hematology, Kanazawa University Hospital, Takaramachi 13-1, Kanazawa, Ishikawa 920-8640, Japan

2 Department of Environmental and Preventive Medicine, Kanazawa University, Takaramachi 13-1, Kanazawa, Ishikawa 920-8640, Japan severe disease can develop even in young people and those without comorbidities, and many points remain unclear regarding what factors contribute to the outcomes. Some genetic components may also be involved. In fact, sex differences have been reported in immunological responses to SARS-CoV-2 [4] and that relatively few people with blood type $\mathrm{O}$ are infected [5].

Respiratory failure is the most common cause of death, but coagulation activation accompanied by excessive immune/inflammatory reactions (representing the so-called cytokine storm), thrombosis and disseminated intravascular coagulation (DIC), and progression to multiple-organ failure are also causes of death [6-10]. In particular, thrombosis and DIC can lead to a rapid deterioration in condition.

\section{COVID-19-associated coagulopathy}

The most frequently described report related to COVID-19 coagulopathy is an increase in plasma D-dimer levels. Many studies have discussed the relationship between elevated D-dimer levels and prognosis [2, 11-13]. 
D-Dimer is produced in the blood as a result of degradation of stabilized fibrin polymer (fibrin crosslinked with factor XIII) by plasmin. That is, thrombus is formed in the body by coagulation activation, and is decomposed by fibrinolytic activation. Many papers have reported that elevated levels of D-dimer are associated with severity. However, if a large amount of thrombus forms in the body but it is not dissolved (representing the most serious condition for the body), the increase in D-dimer may be mild. Specifically, in the suppressed-fibrinolytic-type DIC caused by sepsis, the increase in D-dimer is relatively mild even in severe cases such as death [14]. Thus, it should be noted that the degree of the increase in D-dimer is not directly correlated with the severity of the pathological condition.

\section{Problems of previous studies using coagulation tests}

D-Dimer is certainly a useful marker in assessing the thrombotic pathology of COVID-19. However, previous reports discussing coagulation and fibrinolysis in COVID-19 have shown the following problems:

1) Most studies have suggested that the prognosis can be estimated based on the level of D-dimer on admission (few studies have discussed changes in D-dimer levels over time);
2) Among the coagulation tests, D-dimer and prothrombin time (PT) are often measured, but fibrinogen, activated partial thromboplastin time (APTT), and fibrin/fibrinogen degradation products (FDP) are often left measured; and.

3) Very few reports have examined thrombin-antithrombin complex (TAT) and plasmin- $\alpha_{2}$ plasmin inhibitor complex (PIC), which are essential markers for coagulation and fibrinolysis activation, respectively. No studies appear to have evaluated with soluble fibrin (SF).

\section{Dynamic fluctuations in coagulation and fibrinolysis}

Figure 1 shows the results of classifying COVID-19 patients into survivors and non-survivors and tracking the coagulation/fibrinolytic pathologies [6]. That study was very valuable, not only because many coagulation markers were investigated in COVID-19 patients, but also because these markers were followed-up regularly. That paper is cited in almost every study discussing the coagulation and fibrinolysis pathology of COVID-19. The paper has three important points:

\section{High DIC complications in non-survivors}

The rate of COVID-19 complicated by DIC has been reported as $0.6 \%$ for survivors and $71.4 \%$ for non-survivors
Fig. 1 Time-dependent changes in coagulation and fibrinolytic markers in COVID-19 (modified from Reference [6]. $P T$ prothrombin time, APTT activated partial thromboplastin time, $D D$ D-dimer, FDP fibrin/fibrinogen degradation products, $\mathrm{Fbg}$ fibrinogen, $A T$ antithrombin
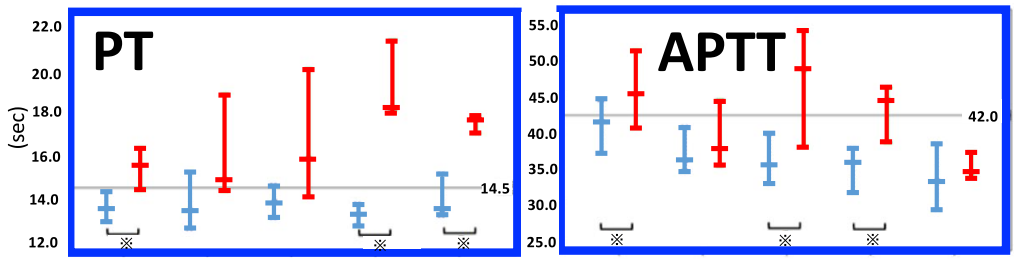

Survivors
Non-Survivors
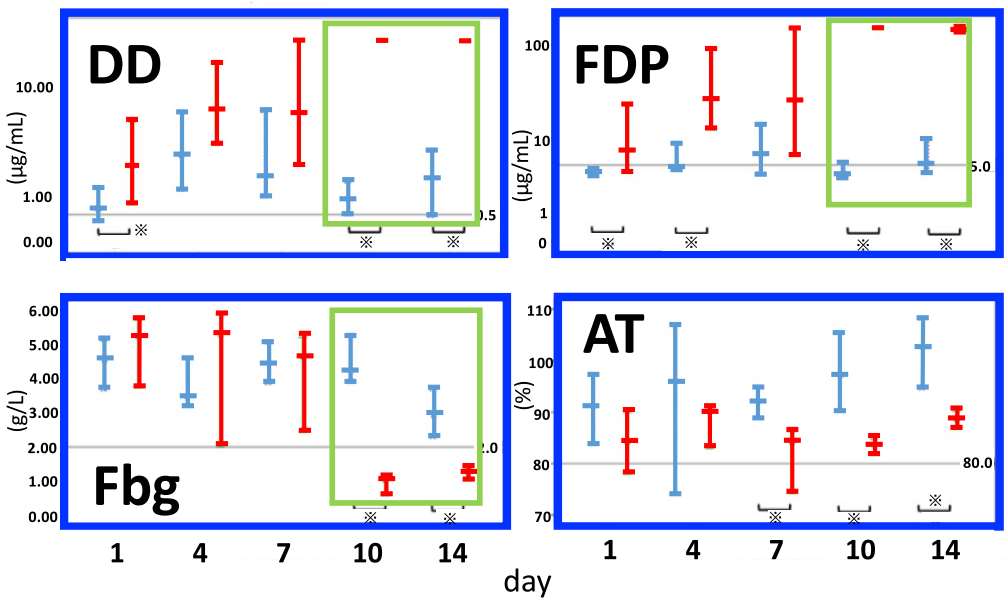
[6]. Thus, the rate of complication by DIC in fatal cases has been judged as very high. In other words, few survivors have DIC complications.

Attention should be paid to the severe coagulopathy on Days 10 and 14 in fatal cases. Among test results, FDP $\geq 100 \mu \mathrm{g} / \mathrm{mL}$, D-dimer of about $20 \mu \mathrm{g} / \mathrm{mL}$, and fibrinogen of about $100 \mathrm{mg} / \mathrm{dL}$ were major abnormal findings. Since levels of D-dimer were mildly increased, while levels of FDP were extremely increased, a divergence phenomenon was observed between FDP and D-dimer levels. PT was clearly prolonged, but APTT prolongation was less noticeable. The decrease in antithrombin was also inconspicuous (maintained at $\geq 80 \%$ ) (Fig. 1) [6].

These findings are significantly different from the suppressed-fibrinolytic-type DIC caused by sepsis, but rather consistent with the enhanced-fibrinolytic-type DIC [14]. In suppressed-fibrinolytic-type DIC, the increases in FDP and D-dimer are relatively mild, and the inflammatory reaction causes a rare decrease in fibrinogen. DIC in fatal cases with COVID-19 is very different from septic DIC.

\section{Prediction of prognosis by $D$-dimer level on admission}

Many studies have suggested that the prognosis of COVID19 can be estimated by levels of D-dimer on admission [2, 11-13], but the paper by Tang et al. was a pioneering work [6]. However, accurate assessment of prognosis cannot be achieved with admission data alone.

\section{Large fluctuations in coagulation and fibrinolysis}

Interestingly, large fluctuations in coagulation and fibrinolysis markers were observed between Days 7 and 10 (Fig. 1) [6]. In fatal cases, fibrinogen was as high as about $400 \mathrm{mg} /$ dL on Day 7, but dropped sharply to about $100 \mathrm{mg} / \mathrm{dL}$ on Day 10 (only 3 days later). FDP and D-dimer levels increased sharply in just 3 days. On the other hand, among survivors, almost no changes were seen during this same period.

These short-term fluctuations mean that changes in pathology may be missed if coagulation and fibrinolysis markers are not followed regularly. Naturally, if the condition changes, treatment also needs to change. Attention should be paid to major bleeding during the pathological condition of enhanced-fibrinolytic-type DIC.

Thus, with COVID-19, coagulation and fibrinolytic pathologies may change rapidly within a short period of time, and follow-up is required every 2-3 days.

Thrombosis (particularly venous thromboembolism) has been noted to show a high incidence of COVID-19, and is certainly often associated with the severity of cases [15]. However, in critical cases of death (autopsy cases), not only thrombi, but also considerable bleeding has been observed
[16]. This means that in fatal cases, there is a possibility that suppressed-fibrinolytic-type DIC has changed to an enhanced-fibrinolytic-type DIC, representing a subject for future study.

\section{Coagulation tests required for COVID-19}

To correctly evaluate coagulation and fibrinolytic pathology in COVID-19, performing the tests shown in Table 1 is important. Among reports in leading journals, even if D-dimer and PT are examined, few have examined fibrinogen, FDP, APTT, etc.

APTT prolongation was frequently seen in COVID-19, and the presence of lupus anticoagulant was identified at a high rate $[17,18]$. It should be noted that APTT testing in patients with COVID-19 also provides information useful for screening for lupus anticoagulant as well as monitoring heparin.

In enhanced-fibrinolytic-type DIC, FDP fluctuates with better sensitivity than D-dimer [6, 13, 14]. By measuring both FDP and D-dimer, the divergence phenomenon between the two markers in enhanced-fibrinolytic-type DIC can be confirmed, so frequent measurement of both markers is desirable.

Fibrinogen can also be measured regularly to check for changes in the type of DIC. In particular, when fibrinogen levels decrease sharply, the disease type may have changed from suppressed-fibrinolytic-type DIC to enhanced-fibrinolytic-type DIC.

TAT, a coagulation activation marker, and PIC, a fibrinolytic activation marker, are essential markers for accurately evaluating coagulation and fibrinolytic pathology in COVID19. By measuring these markers, the coagulation and fibrinolytic pathologies of COVID-19 will be greatly clarified. In cases with DIC in which PIC is markedly increased, caution is required, because major bleeding is likely to occur when $\alpha_{2}$ plasmin inhibitor is reduced to less than half. In cases where antithrombin activity is significantly reduced, the sensitivity of TAT may be reduced. In such cases, evaluation with soluble fibrin (SF) may be useful.

Extracorporeal membrane oxygenation (ECMO) may be required in severe cases of COVID-19. Schmidt et al. reviewed the outcomes of COVID-19 patients under ECMO that could be followed-up to Day 60, reporting a mortality rate of $31 \%$, major bleeding in $42 \%$, and hemorrhagic infarction in 5\% [19]. If no adverse events of bleeding were encountered, better results could be expected. Bleeding symptoms when undergoing ECMO are often considered adverse events due to heparin used to maintain the ECMO circuit. However, according to Schmidt et al., the intensity of anticoagulant therapy was appropriate [19] and was unlikely to be the main cause of bleeding. 
Table 1 Coagulation and fibrinolysis tests to be performed in COVID-19

\begin{tabular}{|c|c|}
\hline Markers & Significance of test \\
\hline Platelets & Decreased due to various causes (see text) \\
\hline PT & $\begin{array}{l}\text { Screening test for vitamin K deficiency (diagnosis confirmed by PIVKA-II) } \\
\text { Evaluation of liver failure }\end{array}$ \\
\hline APTT & $\begin{array}{l}\text { UFH monitoring } \\
\text { LA screening test } \\
\text { Screening test for acquired hemophilia }\end{array}$ \\
\hline Fibrinogen & $\begin{array}{l}\text { Diagnosis of DIC (particularly enhanced-fibrinolytic-type DIC). Beware of short-term dips within a few days } \\
\text { If fibrinogen rises, the patient is in a hypercoagulable state } \\
\text { Evaluation of liver failure }\end{array}$ \\
\hline FDP/D-dimer & $\begin{array}{l}\text { Diagnosis of DIC (particularly enhanced-fibrinolytic-type DIC). Watch out for short-term spikes within a few days. } \\
\text { In enhanced-fibrinolytic-type DIC, FDP increases markedly, but D-dimer increases only mildly to moderately, so a } \\
\text { divergence phenomenon is observed between FDP and D-dimer levels } \\
\text { Diagnosis of macro- or microthrombosis } \\
\text { Reflecting lung damage }\end{array}$ \\
\hline Antithrombin & $\begin{array}{l}\text { Evaluation of liver failure } \\
\text { If the activity is decreased in patients with DIC, consider administration of a concentrated antithrombin preparation }\end{array}$ \\
\hline TAT & Evaluation of coagulation activation \\
\hline PIC & Evaluation of fibrinolytic activation \\
\hline$\alpha_{2}$ PI & $\begin{array}{l}\text { If } \alpha_{2} \text { PI activity is significantly decreased in a case where PIC is significantly increased, major bleeding is likely to } \\
\text { occur }\end{array}$ \\
\hline VWF antigen and activity & $\begin{array}{l}\text { Screening test for acquired von Willebrand syndrome. In acquired von Willebrand disease, VWF activity is reduced } \\
\text { compared to the amount of VWF antigen }\end{array}$ \\
\hline
\end{tabular}

$P T$ prothrombin time, APTT activated partial thromboplastin time, FDP fibrin/fibrinogen degradation products, TAT thrombin-antithrombin complex, $P I C$ plasmin- $\alpha_{2}$ plasmin inhibitor complex, $\alpha_{2} P I \alpha_{2}$ plasmin inhibitor, $V W F$ von Willebrand factor, $U F H$ unfractionated heparin, $L A$ lupus anticoagulant, $D I C$ disseminated intravascular coagulation

The following mechanisms should thus be considered as the reason for bleeding under ECMO:

1) Complications of enhanced-fibrinolytic-type DIC: described above;

2) Vascular endotheliitis: Severe COVID-19 is considered to cause severe vascular endothelial injury and vascular fragility [20];

3) Acquired von Willebrand syndrome: The large multimer of von Willebrand factor is known to be decomposed by high shear stress during extracorporeal circulation such as ECMO [21, 22]. In this case, von Willebrand factor activity is reduced as compared with the amount of von Willebrand factor antigen. A von Willebrand factor multimer structural analysis is required for definitive diagnosis.

In COVID-19, not only thrombosis, but also bleeding complications are likely to be seen, and the coagulation tests shown in Table 1 need to be repeated to prevent them.

\section{Macrothrombosis}

In COVID-19, both arterial and venous thrombosis have been reported due to the strong thrombotic tendency. Specifically, arterial thrombosis includes cerebral infarction, myocardial infarction, and limb arterial thrombosis, and venous thrombosis includes deep vein thrombosis (DVT) and pulmonary thromboembolism (PTE). In general, DVT and PTE may occur at the same time, and have been collectively referred to as venous thromboembolism (VTE). Of these thromboses, VTE, and PTE in particular, is the most common in COVID-19 [23] (Fig. 2).

In addition, as a characteristic of VTE in COVID-19, PTE can develop due to the arrival of DVT thrombus, but more often, PTE develops even without DVT. To be precise, pulmonary thrombosis (PT) is more frequent than pulmonary embolism (PE) [24].

A study of 184 severe COVID-19 cases admitted to the ICU found 75 cases of thrombosis [25]. The breakdown of thrombosis was PTE in 65 cases, DVT in 3 cases, cerebral 


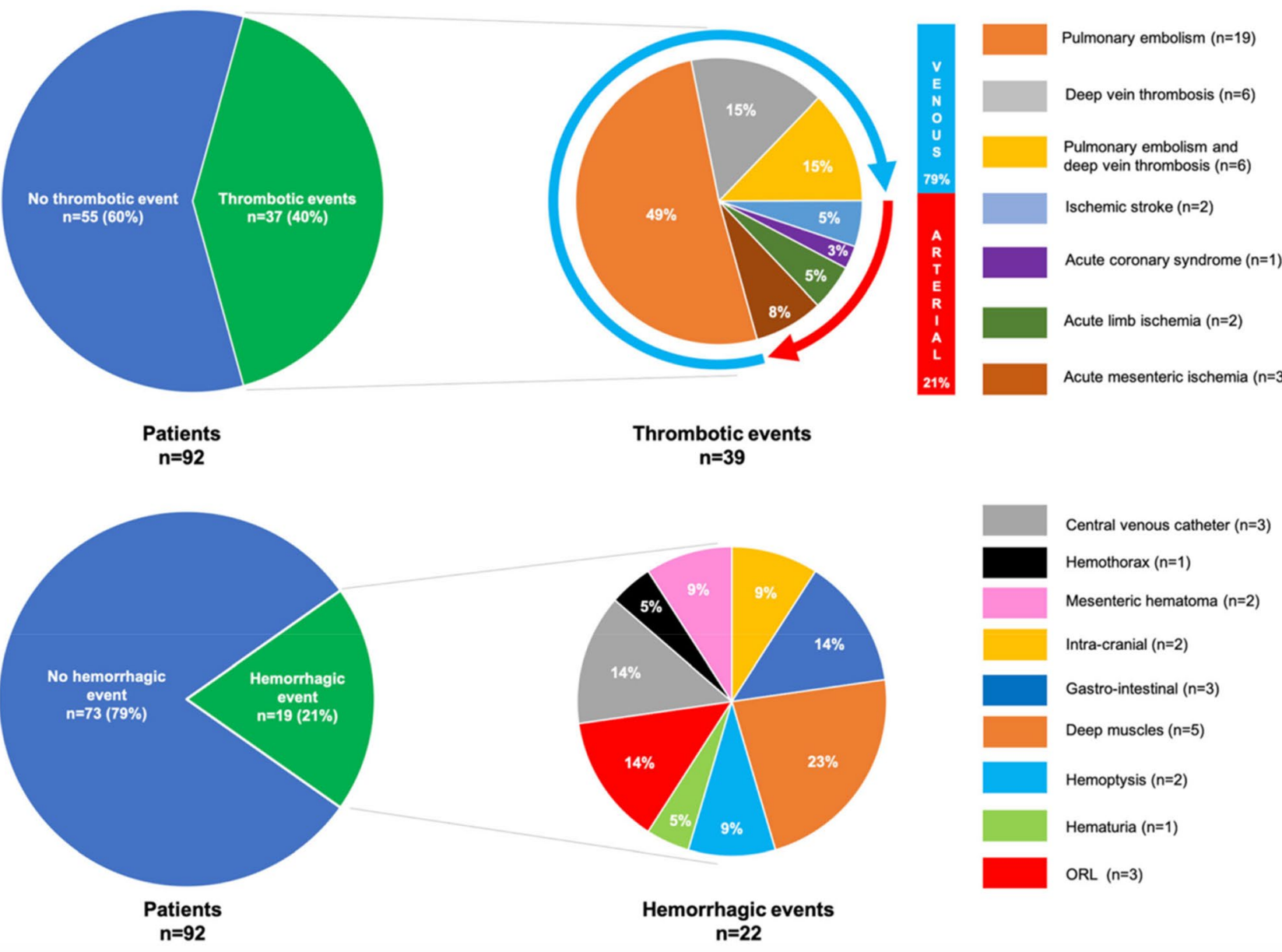

Fig. 2 Sites of thrombosis and bleeding in COVID-19. (Quoted from Reference [23]

infarction in 5 cases, and systemic arterial embolism in 2 cases. After all, PTE makes up the overwhelming majority of thrombosis in severe cases and DVT is not so common. Therapeutic administration of anticoagulant therapy did not lead to suppression of the onset of thrombosis [25].

One report classified and examined ICU inpatients (severe cases) and general ward inpatients (mild cases) [26]. About $60 \%$ of ICU inpatients had VTE, compared to about $10 \%$ of general ward inpatients. Cumulative incidence of VTE increased gradually up to 3 weeks in ICU patients and up to 1 week in general wards, with no subsequent new onset in either group. In other words, attention to VTE in the early stages of hospitalization is considered particularly important. Also in that report, VTE developed even if anticoagulant therapy was initiated prophylactically [26].

In the future, reports on the incidence of thrombosis from Japan are also awaited. However, you must keep in mind the level to which the inspection has been carried out. For example, in patients under ventilator or ECMO management, onset of cerebral infarction may be overlooked and diagnostic imaging may not be performed promptly. In addition, a definitive diagnosis of VTE cannot be made without contrast-enhanced CT of the chest and lower limb vein echography. A dilemma exists regarding the risk of institutional transmission of COVID-19 and how vigorously the diagnosis of thrombosis should be pursued.

\section{Microthrombosis}

Macrothrombosis such as VTE can be diagnosed by imaging modalities such as contrast-enhanced CT, but the existence of multiple microthromboses at the microscopic level, and thus unable to be diagnosed by imaging, has been clarified on autopsy. In the autopsy cases of Fox et al., gross findings showed thrombi in peripheral blood vessels of the lung and enlargement of the right ventricle, but microscopic observation at the same time showed many thrombi in the small arteries and small veins of the lung [16]. These thrombi contained both fibrin and platelet components. Since it is accompanied by vascular endothelial damage, the pathophysiology of thrombotic microangiopathy (TMA) may 
be added to the lungs, but this point is a matter for future investigation.

In an autopsy study by Lax et al., microscopic thrombi were found in the small to middle-sized arteries of the lungs in all 11 cases, even though prophylactic anticoagulant therapy had been administered in 10 of the 11 cases. Eight cases showed pulmonary infarction [27]. Interestingly, VTE was not diagnosed in any of the cases before death.

In an autopsy study of 38 cases by Carsana et al., microthrombi (containing platelets and fibrin) were observed in the pulmonary microarteries in 33 cases (87\%) [28]. In all 26 cases for which D-dimer could be examined, levels increased more than 10 times the upper limit of normal. What was noteworthy in that report was that not only the presence of thrombosis, but also alveolar hemorrhage was observed in 33 cases $(87 \%)$ with the same frequency. Although no markers to accurately assess fibrinolytic activation were measured in that paper, the pathology of enhanced-fibrinolytic-type DIC may have been present in those fatal cases.

One interesting report compared acute respiratory distress syndrome (ARDS) caused by COVID-19 and influenza [29]. Diffuse alveolar damage (DAD) was found in both types. However, COVID-19 showed severe vascular endothelial damage (presence of virus in endothelial cells, destruction of cell membranes) and extensive thrombi. In particular, when compared at the alveolar capillary level, the degree of microthrombosis was 9 times higher in COVID-19 than in influenza, and the higher degree of microthrombosis in the lungs of COVID-19 was conspicuous. Regarding angiogenesis, COVID-19 showed 2.7 times as much as influenza, but the new blood vessels did not display normal antithrombotic function, and were thus considered to accelerate thrombosis.

\section{Pulmonary intravascular coagulopathy}

In severe COVID-19, the thrombotic tendency is systemic, with a strong immunoinflammatory response described as a "cytokine storm". However, the opinion has been put forward that this phenomenon should instead be called "pulmonary intravascular coagulopathy", as opposed to DIC, because the thrombosis occurs overwhelmingly in the lungs rather than the whole body [30-33]. This so-called pulmonary intravascular coagulopathy shows not only macrothrombosis in the lung, but also frequently the more troublesome microthrombosis in a wide area of lung. In other words, anticoagulant therapy is needed while assuming microthrombosis of the lung, which cannot be detected from contrast-enhanced CT of the chest.

Pathologically proving microthrombosis during survival may be difficult, but especially in cases of high D-dimer, the presence of thrombosis (microthrombosis) is assumed even if not diagnosed from diagnostic imaging. A therapeutic strategy for antithrombotic therapy should be developed for such patients.

The site of SARS-CoV-2 has been examined at autopsy [34]. Although also present in the kidneys, liver, heart, brain, and blood, the amount of SARS-CoV-2 detected in the respiratory region is overwhelmingly greater. This is related to the degree of expression of angiotensin-converting enzyme 2 (ACE2), which represent a host-side receptor for SARSCoV-2 in each organ. COVID-19 is known to occur less frequently in children, but this is attributed to the low expression of ACE2 in children [35].

\section{Origin of $\mathrm{D}$-dimer}

Normally, an increase in D-dimer is thought to reflect the activation of both coagulation and fibrinolysis in vivo. In contrast, one report has discussed the origin of D-dimer in COVID-19. The idea of that paper was that the rise in D-dimer reflects the degradation products of fibrin accumulating in the alveoli and lung parenchyma as a result of lung injury [36]. In other words, D-dimer is considered to move from the local lung to the bloodstream. Indeed, given that the origin of D-dimer is fibrin formed locally in the lungs, D-dimer could thus be easily understood to be associated with the degree and prognosis of lung injury.

D-Dimer often rises in patients with massive pleural effusion, massive ascites, and massive hematoma, and this is thought to be due to the movement of D-dimer from pleural effusion, ascites and hematoma into the bloodstream. A similar situation may be present in COVID-19. Proving that D-dimer moves from the alveoli into the bloodstream may be difficult, but the concept is interesting.

\section{Decreased platelet and lymphocyte counts}

Several studies have discussed the relationship between prognosis of COVID-19 and platelet count [37-39]. Among these, one report examined 1476 cases from a single facility [37], of whom 238 patients (16.1\%) died. Mortality rates were reported as $92.1 \%, 61.2 \%, 17.5 \%$, and $4.7 \%$ when minimum platelet counts were $0-5 \times 10^{4} / \mu \mathrm{L}, 5-10 \times 10^{4} /$ $\mu \mathrm{L}, 10-15 \times 10^{4} / \mu \mathrm{L}$, and $\geq 15 \times 10^{4} / \mu \mathrm{L}$, respectively. When the platelet count fell below $10 \times 10^{4} / \mu \mathrm{L}$ during the course of treatment, the prognosis became particularly severe. Furthermore, if the platelet count dropped below $5 \times 10^{4} / \mu \mathrm{L}$, the situation was considered hopeless if no breakthrough treatment was given. The cause of decreasing platelet counts was considered to be DIC in that paper [37].

Many drugs used during the treatment of COVID-19 may result in drug-induced decreases in platelet production (myelosuppression). Such circumstances are easily distinguished 
Table 2 Causes of decreased platelet counts in COVID-19

\begin{tabular}{ll}
\hline 1$)$ & COVID-19 itself \\
2) & Disseminated intravascular coagulation (DIC) \\
$3)$ & Antiphospholipid antibody syndrome (APS) \\
$4)$ & Immune thrombocytopenic purpura (ITP) \\
$5)$ & Hemophagocytic syndrome (HPS) \\
$6)$ & Heparin-induced thrombocytopenia (HIT) \\
$7)$ & Drug-induced myelosuppression \\
$8)$ & Pseudo-thrombocytopenia \\
\hline
\end{tabular}

by checking the immature platelet fraction (IPF). If IPF rises, myelosuppression can be ruled out. Currently, the number of facilities that can measure IPF is increasing in Japan, so this investigation should be actively utilized. Mean platelet volume (MPV) and platelet distribution width (PDW) can also be used to distinguish whether the cause of decrease in platelet count is myelosuppression [40, 41]. In fact, IPF correlates positively with MPV and PDW. In addition, MPV and PDW are advantageous, because the data can be collected using standard equipment in all medical institutions and for all cases. However, one limitation of MPV and PDW is that they cannot be calculated if the platelet count is significantly reduced.

Decreased platelet counts appear to be seen in COVID19 itself, but many causes of decreased platelet counts have been reported (Table 2). As mentioned above, various reports have described the complication of DIC [6-10]. Antiphospholipid antibodies (anticardiolipin antibody and lupus anticoagulant) appear at a high rate [17, 18, 42-44]. If thrombosis is seen, antiphospholipid antibody syndrome is diagnosed. However, antiphospholipid antibodies long been known to show temporary positivity in viral infections (in this case, unrelated to thrombosis). The extent to which antiphospholipid antibodies in COVID-19 are associated with thrombosis warrants further study [45]. Immune thrombocytopenic purpura (ITP) have also been reported in COVID-19 [46-48]. If a sharp and marked drop in platelet count is present, ITP is possible if DIC is negative. Hemophagocytic syndrome has also been reported with cytokine storms [49, 50]. In COVID-19 cases, ready performance of bone marrow examination is presumably difficult, so many cases of hemophagocytic syndrome may go undiagnosed. Along with proper diagnosis, how to address this finding is a topic for further study [51-53].

Heparin is often used during the treatment of COVID19 , and heparin-induced thrombocytopenia (HIT) is often reported $[54,55]$. This diagnosis should not be delayed, and proactive measurement of HIT antibodies is needed.

There are also reports of pseudothrombocytopenia [56]. In this report, treatment with COVID-19 eliminated the phenomenon of pseudothrombocytopenia, as well as the disappearance of SARS-Cov-2 antibody. The association between SARS-Cov-2 antibody and pseudothrombocytopenia has been discussed.

Lymphocytes are known to decrease in particularly severe cases of COVID-19 [1, 57, 58]. Both CD4- and CD8-positive cells are decreased, and a strong correlation exists between lymphocyte count and CD4-positive cells [57, 59]. In addition, CD4-positive cells show reduced IFN- $\gamma$ production [57]. These changes are associated with disease severity, and thus should be kept in mind during the development of future treatments. Some studies have suggested that the neutrophil-to-lymphocyte ratio is associated with the severity and prognosis of COVID-19 [58, $60,61]$.

\section{Treatment strategy for COVID-19}

Treatment strategy should be changed according to the severity and stage of COVID-19, rather than applying a uniform treatment (Fig. 3). In addition, therapeutic methods and drugs have been listed in various candidate steps, starting from the first-step therapeutic strategy to prevent SARS-CoV-2 from invading the host cell, to final-stage cytokine storm control [62-65].

\section{Antiviral treatment for COVID-19}

Several known drugs and treatment methods represent candidate therapeutic agents from the viewpoint of antiviral effect (Table 3). At present, some treatments appear not very effective and others seem promising. Antiviral treatment is considered to be the most significant, particularly in the early stages of infection (Fig. 3).

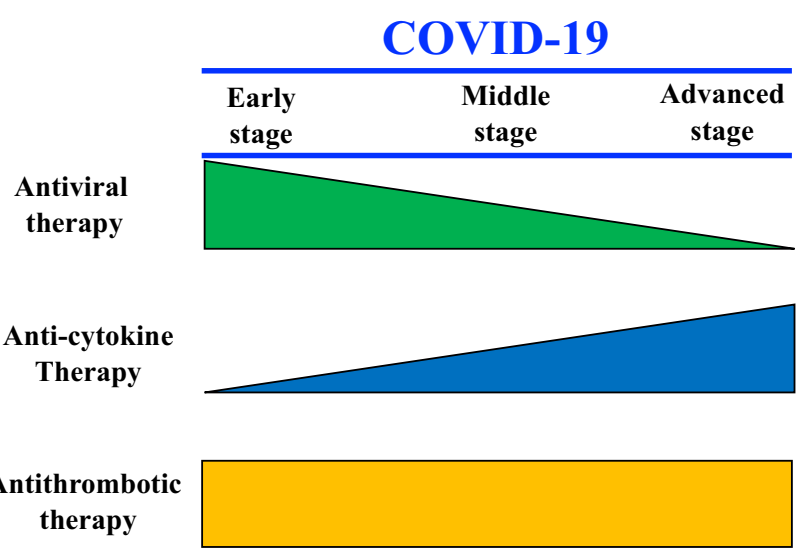

Fig. 3 Stage of COVID-19 and concept of treatment (created by the authors) 
Table 3 Treatment for COVID-19

1 Antiviral drug (anti-SARS-Cov-2 action)

1) Favipiravir (Abigan): RNA polymerase inhibitor. Influenza drug

2) Remdesivir (Beckley): RNA polymerase inhibitor. Ebola bleeding drug. Special approval on May 7, 2020 in Japan

3) Ivermectin (Stromectol): Macrolide antibiotic. Anthelmintic

4) Hydroxychloroquine (Plaquenil): Antimalarial drug. SLE therapeutic drug

5) Lopinavir/ritonavir combination drug (Kaletra): Protease inhibitor. HIV treatment

6) Ciclesonide (Alvesco): Inhaled steroid asthma treatment. Has anti-SARS-CoV-2 action

7) Nafamostat (Futhan, Coahibitor, etc.): Serine protease inhibitor. A therapeutic drug for DIC and pancreatitis in Japan. Inhibits the serine protease TMPRSS2

8) Camostat (Foipan): A serine protease inhibitor. A remedy for pancreatitis in Japan. The inhibitory effects on TMPRSS2 are weaker than those of nafamostat

9) Vaccine: Under development by many companies

10) Convalescent plasma treatment: Expected therapeutic effects through antibody obtained from the serum of convalescent patients

2 Treatment of cytokine storm

1) Tocilizumab, salilumab: anti-IL-6 receptor antibody

2) Anakinra: IL-1 receptor antagonist

3) JAK inhibitor

4) Anti-GM-CSF drug

5) Anti-complement antibody

6) Anti-TNF drug

7) Dexamethasone

8) Blood purification therapy using a cytokine adsorption column

3 Antithrombotic therapy

1) Unfractionated heparin (+ AT preparation: DIC with AT activity $\leq 70 \%$ is covered by insurance)

2) Low molecular weight heparin (+AT preparation: as above)

3) DOAC (anti-Xa drug insurance coverage is venous thromboembolism)

4) Thrombomodulin preparation (insurance coverage is DIC)

5) Argatroban (Insurance coverage is for acute cerebral infarction, chronic arterial occlusion, HIT, etc.)

6) tPA: Reports have described both systemic administration and inhalation

The above is described regardless of insurance coverage. Please confirm the insurance coverage in the package insert

\section{Treatment for cytokine storm}

Many anti-cytokine therapies have been investigated, but the most reported is the anti-IL-6 receptor antibody tocilizumab [66-69]. Future development is expected, including combination therapies with other drugs. When the pathology of COVID-19 has progressed, the weight of cytokine storm treatment is considered to be significantly increased.

\section{Treatment for thrombosis}

Heparin is the most frequently used anticoagulant therapy for COVID-19. In countries other than Japan, low-molecular-weight heparin (LMWH) is often used. In Japan, LMWH (dalteparin) is approved for use by the insurance system only for DIC and hemodialysis, and so in principle cannot be used for COVID-19 in the absence of DIC. Therefore, at present (as of October 2020), unfractionated heparin is estimated to be used more frequently than dalteparin in Japan.
Heparin treatment for COVID-19 is expected to have anticoagulant, antiviral and anti-inflammatory effects [70-73].

\section{Combination therapy of heparin and nafamostat for COVID-19}

Nafamostat is a serine protease inhibitor that strongly inhibits proteolytic enzymes such as thrombin, plasmin, and trypsin [74]. Nafamostat has been used in Japan for over 30 years to treat DIC and pancreatitis. The optimal dose of nafamostat varies depending on the purpose of use, and a higher dose (about 10 times greater) can be used for DIC than for pancreatitis. Nafamostat differs from heparin, in that no side effects of bleeding are seen even when used at DIC doses. Nafamostat is compatible with enhancedfibrinolytic-type DIC because of the strong antifibrinolytic activity [14, 74]. In Japan, nafamostat is often effective even for enhanced-fibrinolytic-type DIC associated with aortic aneurysm and malignant tumors, where the underlying 
pathology does not improve. COVID-19 shows the characteristics of enhanced-fibrinolytic-type DIC in advanced cases as described above, and nafamostat is thus considered to be a promising candidate.

However, the problem with nafamostat is the weaker anticoagulant effect compared to the antifibrinolytic effect [74]. A combination of heparin and nafamostat to overcome this weakness may thus be even more effective [75].

\section{Three reasons nafamostat is effective against COVID-19}

\section{Anti-coronavirus action}

Hoffmann et al. reported that ACE2 and transmembrane protease serine 2 (TMPRSS2) present in host cells are essential for coronaviruses such as SARS-CoV-2 to infect alveolar epithelial cells [76]. Inoue et al. reported in 2016 that nafamostat can inhibit the infection of host cells by MERS-CoV, through inhibition of TMPRSS2 activity [77]. Nafamostat can also block the invasion of SARS-CoV-2 into host cells [78-80]. Injectable nafamostat has more than 10 times the inhibitory activity against coronavirus invasion as the serine protease inhibitor camostat (an oral drug for treating pancreatitis in Japan) [79, 80]. Moreover, when nafamostat is used for DIC as described above, about 10 times the dose used for pancreatitis can be administered.

\section{Beneficial effects on DIC}

COVID-19 is an infectious disease, but shows many differences from the suppressed-fibrinolytic-type DIC caused by other severe infectious diseases. Significant fibrinolytic activation by cytokine storm is expected in advanced, severe cases of COVID-19. We have also confirmed that, as reported by Tang et al. [2], some cases of severe COVID19 show markedly increased FDP and markedly decreased fibrinogen. In such severe cases, one characteristic is a significant increase in not only TAT, as a coagulation activation marker, but also PIC, as a fibrinolytic activation marker. We have encountered cases in which these increases in TAT and PIC often improve dramatically with heparin and nafamostat combination therapy. Nafamostat is a compatible treatment for DIC associated with COVID-19 [75].

\section{Anti-plasmin action}

Plasmin has been reported to increase the pathogenicity and infectivity of the SARS-CoV-2 virus by cleaving the S protein [81]. Nafamostat has antiplasmin activity [74] and is expected to reduce the pathogenicity and infectivity of SARS-CoV-2. Tranexamic acid is known as a drug exerting strong antiplasmin (antifibrinolytic) activity. Tranexamic acid may act suppressively on SARS-CoV-2 in terms of antiplasmin, and actual clinical trials are underway [82]. However, tranexamic acid may induce fatal thrombosis and should not be administered without caution [83]. In that respect, nafamostat can be safely used because of its antiplasmin action in combination with antithrombin action.

Nafamostat is reportedly effective against COVID-19 [84, 85], but the significance of this agent in combination with heparin is hoped to be verified. Nafamostat administered during ECMO treatment (heparin is required) is inevitably administered in combination with heparin. We would like to name this combination "Hepana therapy", as an easy-toremember term.

Nafamostat should be noted to have a side effect of hyperkalemia, so electrolyte levels should be checked regularly.

\section{Prospects for fibrinolytic therapy -including inhalation therapy-}

Heparin, particularly LMWH, is often used to correct the thrombotic condition in COVID-19, but pulmonary embolism is nevertheless seen in about $20-30 \%$ of severe cases [86]. The dose and intensity of anticoagulant therapy is also controversial. Treatment with anticoagulant therapy alone may offer limited efficacy. Fibrinolytic therapy may therefore be effective against COVID-19 [87]. Treatment of existing fibrin, which interferes with pulmonary circulation, using a fibrinolytic drug is expected to improve thrombotic conditions. In fact, systemic administration of the fibrinolytic drug tissue-type plasminogen activator (tPA) to ARDS in COVID-19 has been attempted and appears effective in some cases [88-90].

However, careful attention should be paid to systemic administration of tPA for severe COVID-19 with ARDS. As mentioned above, coagulation and fibrinolytic pathophysiology in COVID-19 can fluctuate significantly within just a few days [6]. Performing systemic fibrinolytic therapy is performed at a time of a marked decrease in fibrinogen is extremely dangerous and may cause fatal bleeding, including cerebral hemorrhage.

On the other hand, treatment by "inhalation" of fibrinolytic substances such as tPA and plasminogen may be associated with relatively little concerns regarding bleeding at any stage of COVID-19 [87, 91, 92]. Inhalation of fibrinolysisrelated substances may dissolve fibrin-containing exudates in the alveolar space to improve alveolar ventilation, and may dissolve fibrin thrombi at the microcirculatory level near the alveoli. Fibrin formed in the lung parenchyma may be expected to dissolve. However, many problems remain to be solved, such as whether the infection spreads in medical institutions via aerosols and how much tPA administered 
by inhalation is transferred to the blood. We expect future developments.

\section{Adsorption therapy as a cytokine storm treatment}

As mentioned above, treatment with anti-IL-6 receptor antibody is one of the candidates for cytokine storm treatment. In addition, we would also like to mention adsorption therapy using cartridges such as polymyxin B (PMX-DHP). This is an extracorporeal circulatory therapy similar to ECMO, with a history of being used mainly for septic endotoxin shock caused by Gram-negative bacilli. Some pros and cons exist regarding the indications of PMX-DHP for COVID-19, partly because this treatment was not sufficiently effective against septic endotoxin shock.

However, for ARDS caused by cytokine storms in influenza 2009 (N1H1), respiratory status reportedly improved dramatically after only $4 \mathrm{~h}$ of PMX-DHP treatment [93]. PMX-DHP could also improve respiratory failure with decreased IL-6 in patients with amyopathic dermatomyositis who presented with respiratory failure due to acute progressive interstitial pneumonia [94]. In addition, the clinical experience of PMX-DHP for ARDS in COVID-19 has been reported in the online journal of the Japanese Society of Infectious Diseases. We are encouraged by a report that PMX-DHP treatment was able to suppress progression of ARDS and subsequently allow weaning from ECMO in 2 out of 3 patients.[95]. Adsorption therapy with PMX-DHP is expected to evolve in the future as a treatment for cytokine storm [96].

\section{Instructive case reports}

Many case reports of COVID-19 have been published. We would like to share some didactic case reports from the perspective of thrombosis.

\section{DVT-only symptoms [97]}

The patient was a 57-year-old woman with chief complaints of swelling, pain, heat, and redness of the left lower limb. She had no fever, cough or shortness of breath. DVT was diagnosed in the left lower limb. Since DVT was present, chest CT was performed to check for the presence of pulmonary emboli, and ground glass shadows were identified in both lung fields. Due to these ground glass shadows, PCR testing was performed and COVID-19 was diagnosed. In other words, the only COVID-19-related symptom present at consultation was thrombosis (DVT).
When encountering DVT of unknown cause, COVID19 should be checked for as a risk factor for DVT, along with checking for antithrombin, protein $\mathrm{C}$, protein $\mathrm{S}$, and antiphospholipid antibody (anticardiolipin antibody, lupus anticoagulant).

\section{Myocardial infarction with numerous thrombi in the coronary arteries [98]}

The patient was a 40-year-old woman who experienced myocardial infarction. Coronary angiography revealed more than 10 thrombi in the coronary arteries at the same time. We feel an unusual thrombotic tendency is present in COVID-19.

\section{Complications of cerebral infarction and cerebral vein sinus thrombosis [99]}

The patient was an 81-year-old man who developed cerebral infarction in the left and right brain at the same time. In this case, cerebral vein sinus thrombosis was also present concomitantly. That is, in the brain, thrombosis occurred in arteries and veins at the same time. This condition is usually unthinkable, but may arise with COVID-19.

\section{Findings similar to chilblains [100]}

Findings of chilblains clearly do not always represent COVID-19, but many such cases have been reported. During the current COVID-19 epidemic, if findings suggestive of chilblains are encountered, COVID-19 should at least be suspected.

\section{Livedo reticularis $[101,102]$}

Livedo reticularis reflects impaired skin circulation. Livedo reticularis is a well-known finding in antiphospholipid antibody syndrome, but is also found in COVID-19.

\section{Conclusion}

Many points remain unclear regarding the pathophysiology of COVID-19. Elucidation of the pathophysiology from the perspective of laboratory hematology is ongoing. D-dimer is an excellent marker, but shows limitations in assessing the pathophysiology of the coagulation abnormalities seen in COVID-19. The pathological condition is expected to be elucidated by adding markers such as TAT, PIC, and SF.

For the treatment of COVID-19, use of different treatment methods according to the pathophysiological condition is desirable, rather than performing uniform treatment. 


\section{References}

1. Huang C, Wang Y, Li X, Ren L, Zhao J, Hu Y, et al. Clinical features of patients infected with 2019 novel coronavirus in Wuhan, China. Lancet. 2020;395(10223):497-506.

2. Zhou F, Yu T, Du R, Fan G, Liu Y, Liu Z, et al. Clinical course and risk factors for mortality of adult inpatients with COVID19 in Wuhan, China: a retrospective cohort study. Lancet. 2020;395(10229):1054-62.

3. Guan WJ, Ni ZY, Hu Y, Liang WH, Ou CQ, He JX, et al. Clinical characteristics of coronavirus disease 2019 in China. N Engl J Med. 2020;382(18):1708-20.

4. Takahashi T, Ellingson MK, Wong P, Israelow B, Lucas C, Klein J, et al. Sex differences in immune responses that underlie COVID-19 disease outcomes. Nature. 2020. https://doi. org/10.1038/s41586-020-2700-3.

5. Zhao J, Yang Y, Huang H, Li D, Gu D, Lu X, et al. Relationship between the ABO blood group and the COVID-19 susceptibility. Clin Infect Dis. 2020. https://doi.org/10.1093/cid/ciaa1150.

6. Tang N, Li D, Wang X, Sun Z. Abnormal coagulation parameters are associated with poor prognosis in patients with novel coronavirus pneumonia. J Thromb Haemost. 2020;18(4):844-7.

7. Mehta P, McAuley DF, Brown M, Sanchez E, Tattersall RS, Manson JJ. COVID-19: consider cytokine storm syndromes and immunosuppression. Lancet. 2020;395(10229):1033-4.

8. Jose RJ, Manuel A. COVID-19 cytokine storm: the interplay between inflammation and coagulation. Lancet Respir Med. 2020;8(6):e46-7.

9. Wright DJM. Prevention of the cytokine storm in COVID19. Lancet Infect Dis. 2020. https://doi.org/10.1016/S1473 -3099(20)30376-5.

10. Iba T, Levy JH, Levi M, Connors JM, Thachil J. Coagulopathy of coronavirus disease 2019. Crit Care Med. 2020;48(9):1358-64.

11. Cummings MJ, Baldwin MR, Abrams D, Jacobson SD, Meyer BJ, Balough EM, et al. Epidemiology, clinical course, and outcomes of critically ill adults with COVID-19 in New York City: a prospective cohort study. Lancet. 2020;395(10239):1763-70.

12. Wu C, Chen X, Cai Y, Xia J, Zhou X, Xu S, et al. Risk factors associated with acute respiratory distress syndrome and death in patients with coronavirus disease 2019 pneumonia in Wuhan, China. JAMA Intern Med. 2020;180(7):934-43.

13. Liao D, Zhou F, Luo L, Xu M, Wang H, Xia J, et al. Haematological characteristics and risk factors in the classification and prognosis evaluation of COVID-19: a retrospective cohort study. Lancet Haematol. 2020;7(9):e671-8.

14. Asakura H. Classifying types of DIC: clinical and animal models. J Intensive Care. 2014;2(1):20.

15. Helms J, Tacquard C, Severac F, Leonard-Lorant I, Ohana M, Delabranche X, et al. High risk of thrombosis in patients with severe SARS-CoV-2 infection: a multicenter prospective cohort study. Intensive Care Med. 2020;46(6):1089-98.

16. Fox SE, Akmatbekov A, Harbert JL, Li G, Quincy Brown J, Vander Heide RS. Pulmonary and cardiac pathology in African American patients with COVID-19: an autopsy series from New Orleans. Lancet Respir Med. 2020;8(7):681-6.

17. Harzallah I, Debliquis A, Drénou B. Lupus anticoagulant is frequent in patients with Covid-19. J Thromb Haemost. 2020;18(8):2064-5.

18. Bowles L, Platton S, Yartey N, Dave M, Lee K, Hart DP, et al. Lupus anticoagulant and abnormal coagulation tests in patients with Covid-19. N Engl J Med. 2020;383(3):288-90.

19. Schmidt M, Hajage D, Lebreton G, Monsel A, Voiriot G, Levy $\mathrm{D}$, et al. Extracorporeal membrane oxygenation for severe acute respiratory distress syndrome associated with COVID19: a retrospective cohort study. Lancet Respir Med. 2020. https://doi.org/10.1016/S2213-2600(20)30328-3.

20. Varga Z, Flammer AJ, Steiger P, Haberecker M, Andermatt R, Zinkernagel AS, et al. Endothelial cell infection and endotheliitis in COVID-19. Lancet. 2020;395(10234):1417-8.

21. Horiuchi H, Doman T, Kokame K, Saiki Y, Matsumoto M. Acquired von Willebrand syndrome associated with cardiovascular diseases. J Atheroscler Thromb. 2019;26(4):303-14.

22. Thomas J, Kostousov V, Teruya J. Bleeding and thrombotic complications in the use of extracorporeal membrane oxygenation. Semin Thromb Hemost. 2018;44(1):20-9.

23. Fraissé M, Logre E, Pajot O, Mentec H, Plantefève G, Contou D. Thrombotic and hemorrhagic events in critically ill COVID19 patients: a French monocenter retrospective study. Crit Care. 2020;24(1):275.

24. Gabrielli M, Lamendola P, Esperide A, Valletta F, Franceschi F. COVID-19 and thrombotic complications: pulmonary thrombosis rather than embolism? Thromb Res. 2020;193:98. https://doi. org/10.1016/j.thromres.2020.06.014.

25. Klok FA, Kruip MJHA, van der Meer NJM, Arbous MS, Gommers D, Kant KM, et al. Confirmation of the high cumulative incidence of thrombotic complications in critically ill ICU patients with COVID-19: an updated analysis. Thromb Res. 2020;191:148-50.

26. Middeldorp S, Coppens M, van Haaps TF, Foppen M, Vlaar AP, Müller MCA, et al. Incidence of venous thromboembolism in hospitalized patients with COVID-19. J Thromb Haemost. 2020;18(8):1995-2002.

27. Lax SF, Skok K, Zechner P, Kessler HH, Kaufmann N, Koelblinger C, et al. Pulmonary Arterial Thrombosis in COVID19 With Fatal Outcome: Results From a Prospective, Single-Center Clinicopathologic case series. Ann Intern Med. 2020;173(5):350-61.

28. Carsana L, Sonzogni A, Nasr A, Rossi RS, Pellegrinelli A, Zerbi $\mathrm{P}$, et al. Pulmonary post-mortem findings in a series of COVID-19 cases from northern Italy: a two-centre descriptive study. Lancet Infect Dis. 2020. https://doi.org/10.1016/S1473 -3099(20)30434-5.

29. Ackermann M, Verleden SE, Kuehnel M, Haverich A, Welte $\mathrm{T}$, Laenger $\mathrm{F}$, et al. Pulmonary vascular endothelialitis, thrombosis, and angiogenesis in Covid-19. N Engl J Med. 2020;383(2):120-8.

30. McGonagle D, Sharif K, O'Regan A, Bridgewood C. The role of cytokines including interleukin-6 in COVID-19 induced pneumonia and macrophage activation syndrome-like disease. Autoimmun Rev. 2020;19(6):102537. https://doi.org/10.1016/j.autre v. 2020.102537.

31. Fogarty H, Townsend L, Ni Cheallaigh C, Bergin C, MartinLoeches I, Browne $\mathrm{P}$, et al. COVID19 coagulopathy in Caucasian patients. Br J Haematol. 2020;189(6):1044-9.

32. McGonagle D, Plein S, O’Donnell JS, Sharif K, Bridgewood C. Increased cardiovascular mortality in African Americans with COVID-19. Lancet Respir Med. 2020;8(7):649-51.

33. Belen-Apak FB, Sarıalioğlu F. Pulmonary intravascular coagulation in COVID-19: possible pathogenesis and recommendations on anticoagulant/thrombolytic therapy. J Thromb Thrombolysis. 2020;50(2):278-80.

34. Puelles VG, Lütgehetmann M, Lindenmeyer MT, Sperhake JP, Wong MN, Allweiss L, et al. Multiorgan and renal tropism of SARS-CoV-2. N Engl J Med. 2020;383(6):590-2.

35. Bunyavanich S, Do A, Vicencio A. Nasal gene expression of angiotensin-converting enzyme 2 in children and adults. JAMA. 2020;323(23):2427-9.

36. Hunt BJ, Levi M. Re the source of elevated plasma D-dimer levels in COVID-19 infection. Br J Haematol. 2020;190(3):e133-4. 
37. Yang X, Yang Q, Wang Y, Wu Y, Xu J, Yu Y, et al. Thrombocytopenia and its association with mortality in patients with COVID-19. J Thromb Haemost. 2020;18(6):1469-72.

38. Liu Y, Sun W, Guo Y, Chen L, Zhang L, Zhao S, et al. Association between platelet parameters and mortality in coronavirus disease 2019: retrospective cohort study. Platelets. 2020;31(4):490-6.

39. Maquet J, Lafaurie M, Sommet A, Moulis G. Thrombocytopenia is independently associated with poor outcome in patients hospitalized for COVID-19. Br J Haematol. 2020;190(5):e276-9.

40. Lee E, Kim M, Jeon K, Lee J, Lee JS, Kim HS, et al. Mean platelet volume, platelet distribution width, and platelet count, in connection with immune thrombocytopenic purpura and essential thrombocytopenia. Lab Med. 2019;50(3):279-85.

41. Kaito K, Otsubo H, Usui N, Yoshida M, Tanno J, Kurihara E, et al. Platelet size deviation width, platelet large cell ratio, and mean platelet volume have sufficient sensitivity and specificity in the diagnosis of immune thrombocytopenia. Br J Haematol. 2005;128(5):698-702.

42. Zhang Y, Xiao M, Zhang S, Xia P, Cao W, Jiang W, et al. Coagulopathy and antiphospholipid antibodies in patients with Covid19. N Engl J Med. 2020;382(17):e38.

43. de Ocáriz XGL, Quismondo NC, Guerrero EV, Rodríguez MR, Díaz RA, Lopez JM. Thrombosis and antiphospholipid antibodies in patients with SARS-COV-2 infection (COVID-19. Int J Lab Hematol. 2020. https://doi.org/10.1111/ijlh.13320.

44. Reyes Gil M, Barouqa M, Szymanski J, Gonzalez-Lugo JD, Rahman S, Billett HH. Assessment of lupus anticoagulant positivity in patients with coronavirus disease 2019 (COVID-19). JAMA Netw Open. 2020;3(8):e2017539.

45. Devreese KMJ, Linskens EA, Benoit D, Peperstraete H. Antiphospholipid antibodies in patients with COVID-19: a relevant observation? J Thromb Haemost. 2020. https://doi. org/10.1111/jth.14994.

46. Zulfiqar AA, Lorenzo-Villalba N, Hassler P, Andrès E. Immune thrombocytopenic purpura in a patient with Covid-19. N Engl J Med. 2020;382(18):e43.

47. Lévesque V, Millaire É, Corsilli D, Rioux-Massé B, Carrier FM. Severe immune thrombocytopenic purpura in critical COVID-19. Int J Hematol. 2020;1:1-5. https://doi.org/10.1007/s12185-02002931-9.

48. Deruelle E, Salem OBH, Hieng SS, Pichereau C, Outin H, Jamme M. Immune thrombocytopenia in a patient with COVID-19. Int J Hematol. 2020;16:1-6. https://doi.org/10.1007/s12185-02002943-5.

49. Dewaele K, Claeys R. Hemophagocytic lymphohistiocytosis in SARS-CoV-2 infection. Blood. 2020;135(25):2323.

50. Debliquis A, Harzallah I, Mootien JY, Poidevin A, Labro G, Mejri A. Haemophagocytosis in bone marrow aspirates in patients with COVID-19. Br J Haematol. 2020;190(2):e70-3.

51. Takami A. Possible role of low-dose etoposide therapy for hemophagocytic lymphohistiocytosis by COVID-19. Int J Hematol. 2020a;112(1):122-4.

52. Loscocco GG. Secondary hemophagocytic lymphohistiocytosis, HScore and COVID-19. Int J Hematol. 2020;112(1):125-6.

53. Takami A. Reply to the letter by Gaetano Loscocco, secondary hemophagocytic lymphohistiocytosis, HScore and COVID-19. Int J Hematol. 2020b;112(1):127.

54. Patell R, Khan AM, Bogue T, Merrill M, Koshy A, Bindal P, et al. Heparin induced thrombocytopenia antibodies in Covid-19. Am J Hematol. 2020. https://doi.org/10.1002/ajh.25935.

55. Warkentin TE, Kaatz S. COVID-19 versus HIT hypercoagulability. Thromb Res. 2020;196:38-51.

56. Li H, Wang B, Ning L, Luo Y, Xiang S. Transient appearance of EDTA dependent pseudothrombocytopenia in a patient with 2019 novel coronavirus pneumonia. Platelets. 2020;31(6):825-6.
57. Chen G, Wu D, Guo W, Cao Y, Huang D, Wang H, et al. Clinical and immunological features of severe and moderate coronavirus disease 2019. J Clin Invest. 2020;130(5):2620-9.

58. Yuan X, Huang W, Ye B, Chen C, Huang R, Wu F, et al. Changes of hematological and immunological parameters in COVID-19 patients. Int J Hematol. 2020;12:1-7. https://doi. org/10.1007/s12185-020-02930-w.

59. Zhou Y, Zhang Z, Tian J, Xiong S. Risk factors associated with disease progression in a cohort of patients infected with the 2019 novel coronavirus. Ann Palliat Med. 2020;9(2):428-36.

60. Fu J, Kong J, Wang W, Wu M, Yao L, Wang Z, et al. The clinical implication of dynamic neutrophil to lymphocyte ratio and D-dimer in COVID-19: a retrospective study in Suzhou China. Thromb Res. 2020;192:3-8.

61. Liang W, Liang H, Ou L, Chen B, Chen A, Li C, et al. Development and validation of a clinical risk score to predict the occurrence of critical illness in hospitalized patients with COVID-19. JAMA Intern Med. 2020;180(8):1081-9.

62. Tay MZ, Poh CM, Rénia L, MacAry PA, Ng LFP. The trinity of COVID-19: immunity, inflammation and intervention. Nat Rev Immunol. 2020;20(6):363-74.

63. Matheson NJ, Lehner PJ. How does SARS-CoV-2 cause COVID-19? Science. 2020;369(6503):510-1.

64. Pons S, Fodil S, Azoulay E, Zafrani L. The vascular endothelium: the cornerstone of organ dysfunction in severe SARSCoV-2 infection. Crit Care. 2020;24(1):353.

65. Romagnoli S, Peris A, De Gaudio AR, Geppetti P. SARSCoV-2 and COVID-19: from the bench to the bedside. Physiol Rev. 2020;100(4):1455-66.

66. Guaraldi G, Meschiari M, Cozzi-Lepri A, Milic J, Tonelli $\mathrm{R}$, Menozzi $\mathrm{M}$, et al. Tocilizumab in patients with severe COVID-19: a retrospective cohort study. Lancet Rheumatol. 2020;2(8):e474-84.

67. Biran N, Ip A, Ahn J, Go RC, Wang S, Mathura S, et al. Tocilizumab among patients with COVID-19 in the intensive care unit: a multicentre observational study. Lancet Rheumatol. 2020;2(10):e603-12.

68. Xu X, Han M, Li T, Sun W, Wang D, Fu B, et al. Effective treatment of severe COVID-19 patients with tocilizumab. Proc Natl Acad Sci U S A. 2020;117(20):10970-5.

69. Toniati P, Piva S, Cattalini M, Garrafa E, Regola F, Castelli F, et al. Tocilizumab for the treatment of severe COVID-19 pneumonia with hyperinflammatory syndrome and acute respiratory failure: a single center study of 100 patients in Brescia, Italy. Autoimmun Rev. 2020;19(7):102568.

70. Liu J, Li J, Arnold K, Pawlinski R, Key NS. Using heparin molecules to manage COVID-2019. Res Pract Thromb Haemost. 2020;4(4):518-23.

71. Lindahl U, Li JP. Heparin-an old drug with multiple potential targets in Covid-19 therapy. J Thromb Haemost. 2020. https:// doi.org/10.1111/jth.14898.

72. Thachil J. Clinical differentiation of anticoagulant and nonanticoagulant properties of heparin. J Thromb Haemost. 2020. https://doi.org/10.1111/jth.14933.

73. Hippensteel JA, LaRiviere WB, Colbert JF, Langouët-Astrié CJ, Schmidt EP. Heparin as a therapy for COVID-19: current evidence and future possibilities. Am J Physiol Lung Cell Mol Physiol. 2020;319(2):L211-7.

74. Aoyama T, Ino Y, Ozeki M, Oda M, Sato T, Koshiyama Y, et al. Pharmacological studies of FUT-175, nafamstat mesilate. I. Inhibition of protease activity in in vitro and in vivo experiments. Jpn J Pharmacol. 1984;35(3):203-27.

75. Asakura H, Ogawa H. Potential of heparin and nafamostat combination therapy for COVID-19. J Thromb Haemost. 2020a;18(6):1521-2. 
76. Hoffmann M, Kleine-Weber H, Schroeder S, Krüger N, Herrler T, Erichsen S, et al. SARS-CoV-2 cell entry depends on ACE2 and TMPRSS 2 and is blocked by a clinically proven protease inhibitor. Cell. 2020;181(2):271-80.

77. Yamamoto M, Matsuyama S, Li X, Takeda M, Kawaguchi Y, Inoue JI, et al. Identification of nafamostat as a potent inhibitor of middle east respiratory syndrome coronavirus $\mathrm{S}$ protein-mediated membrane fusion using the split-protein-based cell-cell fusion assay. Antimicrob Agents Chemother. 2016;60(11):6532-9.

78. Inoue J, Yamamoto M. Identification of an existing Japanese pancreatitis drug, Nafamostat, which is expected to prevent the transmission of new coronavirus infection (COVID-19). Available at: https://www.u-tokyo.ac.jp/focus/en/articles/z0508_00083 .html

79. Yamamoto M, Kiso M, Sakai-Tagawa Y, Iwatsuki-Horimoto K, Imai M, Takeda M, et al. The anticoagulant nafamostat potently inhibits SARS-CoV-2 S protein-mediated fusion in a cell fusion assay system and viral infection in vitro in a cell-type-dependent manner. Viruses. 2020;12(6):629.

80. Hoffmann M, Schroeder S, Kleine-Weber H, Müller MA, Drosten C, Pöhlmann S. Nafamostat mesylate blocks activation of SARSCoV-2: new treatment option for COVID-19. Antimicrob Agents Chemother. 2020;64(6):e00754-e820.

81. Ji HL, Zhao R, Matalon S, Matthay MA. Elevated plasmin(ogen) as a common risk factor for COVID-19 susceptibility. Physiol Rev. 2020;100(3):1065-75.

82. Barker AB, Wagener BM. An ounce of prevention may prevent hospitalization. Physiol Rev. 2020;100(3):1347-8.

83. Ogawa $\mathrm{H}$, Asakura H. Consideration of tranexamic acid administration to COVID-19 patients. Physiol Rev. 2020;100(4):1595-6.

84. Doi K, Ikeda M, Hayase N, Moriya K, Morimura N. Nafamostat mesylate treatment in combination with favipiravir for patients critically ill with Covid-19: a case series. Crit Care. 2020;24(1):392.

85. Jang S, Rhee JY. Three cases of treatment with nafamostat in elderly patients with COVID-19 pneumonia who need oxygen therapy. Int J Infect Dis. 2020;96:500-2.

86. Hasan SS, Radford S, Kow CS, Zaidi STR. Venous thromboembolism in critically ill COVID-19 patients receiving prophylactic or therapeutic anticoagulation: a systematic review and meta-analysis. J Thromb Thrombolysis. 2020;3:1-8. https://doi. org/10.1007/s11239-020-02235-z.

87. Whyte CS, Morrow GB, Mitchell JL, Chowdary P, Mutch NJ. Fibrinolytic abnormalities in acute respiratory distress syndrome (ARDS) and versatility of thrombolytic drugs to treat COVID-19. J Thromb Haemost. 2020;18(7):1548-55.

88. Christie DB 3rd, Nemec HM, Scott AM, Buchanan JT, Franklin CM, Ahmed A, et al. Early outcomes with utilization of tissue plasminogen activator in COVID-19 associated respiratory distress: a series of five cases. J Trauma Acute Care Surg. 2020;89(3):448-52.

89. Choudhury R, Barrett CD, Moore HB, Moore EE, McIntyre $\mathrm{RC}$, Moore PK, et al. Salvage use of tissue plasminogen activator (tPA) in the setting of acute respiratory distress syndrome (ARDS) due to COVID-19 in the USA: a Markov decision analysis. World J Emerg Surg. 2020;15(1):29.
90. Wang J, Hajizadeh N, Moore EE, McIntyre RC, Moore PK, Veress LA, et al. Tissue plasminogen activator (tPA) treatment for COVID-19 associated acute respiratory distress syndrome (ARDS): a case series. J Thromb Haemost. 2020;18(7):1752-5.

91. Wu Y, Wang T, Guo C, Zhang D, Ge X, Huang Z, et al. Plasminogen improves lung lesions and hypoxemia in patients with COVID-19. QJM. 2020;113(8):539-45.

92. Asakura H, Ogawa H. Perspective on fibrinolytic therapy in COVID-19: the potential of inhalation therapy against suppressed-fibrinolytic-type DIC. J Intensive Care. 2020b;8:71.

93. Araki T, Ogawa H, Nakashima A. Endotoxin adsorption therapy for a patient with severe pneumonia resulting from novel influenza A (H1N1) virus infection. Ther Apher Dial. 2011;15(2):207-8.

94. Yasuda H, Ikeda T, Hamaguchi Y, Furukawa F. Clinically amyopathic dermatomyositis with rapidly progressive interstitial pneumonia: the relation between the disease activity and the serum interleukin-6 level. J Dermatol. 2017;44(10):1164-7.

95. Sone H, Yamamoto M, Manaka H, Aida N, Furo M, Kubota A, et al. Three patients who underwent blood purification therapy for COVID-19 infection. The Japanese Association for Infectious Diseases.2020. https://www.kansensho.or.jp/uploads/files/topic s/2019ncov/covid19_casereport_200324_4.pdf (in Japanese)

96. Ogawa $\mathrm{H}$, Kakuchi Y, Asakura $\mathrm{H}$. The adjunctive therapies for early withdrawal from extracorporeal membrane oxygenation. J Card Surg. 2020. in press.

97. Davoodi L, Jafarpour H, Taghavi M, Razavi A. COVID-19 presented with deep vein thrombosis: an unusual presenting. J Investig Med High Impact Case Rep. 2020. https://doi. org/10.1177/2324709620931239.

98. Harari R, Bangalore S, Chang E, Shah B. COVID-19 complicated by acute myocardial infarction with extensive thrombus burden and cardiogenic shock. Catheter Cardiovasc Interv. 2020. https ://doi.org/10.1002/ccd.28992.10.1002/ccd.28992.

99. Malentacchi M, Gned D, Angelino V, Demichelis S, Perboni A, Veltri A, et al. Concomitant brain arterial and venous thrombosis in a COVID-19 patient. Eur J Neurol. 2020. https://doi. org/10.1111/ene.14380.10.1111/ene.14380.

100. Guarneri C, Rullo EV, Pavone P, Berretta M, Ceccarelli M, Natale A, et al. Silent COVID-19: what your skin can reveal. Lancet Infect Dis. 2020. https://doi.org/10.1016/S1473 -3099(20)30402-3.

101. Manalo IF, Smith MK, Cheeley J, Jacobs R. A dermatologic manifestation of COVID-19: transient livedo reticularis. J Am Acad Dermatol. 2020;83(2):700.

102. Droesch C, Hoang M, DeSancho M, Lee EJ, Magro C, Harp J. Livedoid and purpuric skin eruptions associated with coagulopathy in severe COVID-19. JAMA Dermatol. 2020;156(9):1022-4.

Publisher's Note Springer Nature remains neutral with regard to jurisdictional claims in published maps and institutional affiliations. 